\title{
Força e vontade: aspectos teórico-metodológicos do risco em epidemiologia e prevenção do HIV/AIDS
}

\section{Strenght and will: theoretical and methodological issues from the standpoint of risk in epidemiology and HIV/AIDS prevention}

\section{Luís David Castiel}

Departamento de Epidemiologia e Métodos Quantitativos em Saúde. Escola Nacional de Saúde Pública. Fundação Oswaldo Cruz. Rio de Janeiro, RJ - Brasil

\begin{abstract}
Resumo
Aborda-se, sob o ponto de vista do risco em epidemiologia, as propostas de educação em saúde com vistas à prevenção do HIV/AIDS. Levando em conta os resultados insatisfatórios dos programas de educação sanitária, baseados no conceito de risco visando ao controle da pandemia, discutem-se as possíveis premissas subjacentes às referidas propostas. Nelas, se destaca a concepção de racionalidade do receptor de tais conteúdos educacionais. Assim, ficam consideradas as noções que envolvem o entendimento público dos conceitos epidemiológicos. São discutidas limitações do instrumental epidemiológico para dar conta das dimensões interativas no adoecimento pela AIDS. Apresentase uma abordagem que procura levar em consideração tais aspectos.
\end{abstract}

Síndrome de Imunodeficiência Adquirida, prevenção \& controle. Educação em saúde. Risco. Conhecimentos, atitudes e prática.

\begin{abstract}
Health education related to HIV/AIDS prevention is approached from the standpoint of risk in epidemiology. The shortcomings of the outcomes of health programs, in terms of controlling the spread of the disease led the author to consider the premisses that lie behind these programs. One of them is the idea of the rationality of the "receiver" of health information. Notions related to public understanding of concepts produced by epidemiology are considered. Some limitations of epidemiological methods regarding interactive relationships in processes of being affected by AIDS are discussed. A method that deals with interactional aspects is presented.
\end{abstract}

Acquired immunodeficiency syndrome, prevention. Health education. Risk. Knowledge, attitudes, practice.

Correspondência para / Correspondence to: Luís David Castiel - Departamento de Epidemiologia e Métodos Quantitativos em Saúde. Escola Nacional de Saúde Pública/FIOCRUZ. R. Leopoldo de Bulhões, 1480 Sala 829 - Manguinhos - 21041-210 - Rio de Janeiro - RJ - Brasil - Fax (021) 270.6772. E-mail: Castiel @ DCC 001.CICT.FIOCRUZ.BR

Recebido em 10/1/1995. Reapresentado em 2/8/1995. Aprovado em 22/8/1995. 


\section{INTRODUÇÃO}

Propõe-se discutir criticamente, sob o ponto de vista do risco epidemiológico, tópicos relacionados às políticas de prevenção em saúde, seus pressupostos e seus dilemas. Para isto, deve-se partir de um aspecto considerado essencial em qualquer política de saúde bem sucedida dirigida à AIDS, segundo respeitáveis autoridades sanitárias no assunto. Se os requisitos fundamentais para o sucesso na prevenção são: informação e educação; serviços sociais e de saúde; ambiente social adequado (Mann e col. ${ }^{23}$, 1993), desde logo fica claro que os dois últimos itens oferecem mais dificuldades. O segundo tópico, especialmente, envolve além da vontade política, os inevitáveis problemas referentes a recursos financeiros, materiais, humanos e organizacionais. No terceiro, há que lidar com aspectos decorrentes do julgamento quanto a idéia de "adequação" de um "ambiente social" (e como circunscrevê-lo diante da enorme diversidade de fatores e determinantes que envolvem algo desta ordem). Portanto, não parece haver maiores discordâncias em relação ao fato das medidas dirigidas à informação e educação em saúde serem vistas como mais factíveis, acessíveis e econômicas e, por conseguinte, as mais empregadas para lidar com a prevenção do HIV.

A epidemiologia tem contribuído, entre outros aspectos, através de suas elaborações acerca da idéia de "risco", construída a partir das características de transmissibilidade e respectivas vias de entrada do agente etiológico considerado como responsável pela síndrome. Nesta ótica, conforme os padrões de exposição, as probabilidades de ser infectado pelo HIV acompanhariam determinados comportamentos ou exposições a situações encaradas como de "risco", que poderiam ser devidamente mensuradas. Assim, dentro de uma visão racionalizadora, seria possível: 1) prover mecanismo dirigido à vigilância populacional e proporcionar serviços para averigüar se as medidas de prevenção estão sendo efetivas ou não; 2) dimensionar os níveis de assistência e planejar demandas futuras em termos de assistência e alocação de recursos requeridos por indivíduos e comunidades sob diferentes graus de "riscos". Além disto, o risco epidemiológico permitiria ampliar o entendimento público a respeito da prevenção da epidemia (Frankenberg $\left.{ }^{13}, 1994\right)$.

Um dos formatos assumidos pelas campanhas de educação em saúde em diferentes contextos foi o de enfatizar a letalidade da doença. Isto deveria servir como apelo suficiente para estimular as pessoas a evitarem comportamentos de risco: a)reduzir a quantidade de parceiros e b) evitar relações sexuais anais, tanto insertivas como receptivas. Além disto, destacavam a intensidade dos abalos emocionais e sofrimento pessoal que atingiam aos infectados (Danziger $\left.{ }^{11}, 1994\right)$.

Porém, após uma década de experiência, percebe-se que os resultados esperados a partir da educação em saúde por si situaram-se aquém da efetividade almejada. Muitas investigações indicaram reduções significativas no número de parceiros entre homens que fazem sexo entre si. Isto teria diminuído a probabilidade de infecção ao nível agregado. Mas, o uso consistente de preservativos, mais efetivo na prevenção, não parece ter tido a mesma adesão. Mesmo que a maioria dos estudos mostre mudanças importantes no sentido de práticas de sexo seguro em nível agregado, há indicações, em termos individuais, de que muitos homens permanecem adotando comportamentos sexuais de risco (Hospers e Kok ${ }^{18}$, 1995).

Em relação ao importante grupo etário constituído pelos jovens e adolescentes, observouse que a capacidade das campanhas de prevenção contra a AIDS em proporcionarem atitudes preventivas de longo prazo parece ser mais exceção de que regra (Weisse e col. ${ }^{37}$, 1995).

Em suma, atualmente, experts no assunto se manifestam dizendo:

"O fato da informação não ser capaz de provocar mudanças comportamentais de forma confiável, regular e previsível foi documentado inúmeras vezes em várias culturas e contextos, ressaltando a necessidade de uma abordagem abrangente à prevenção, combinando os três elementos essenciais ao seu sucesso" (Mann e col. ${ }^{23}$, 1993)."

Deste modo, tem-se a impressão que informação e educação só podem ser efetivas caso acopladas às duas outras mencionadas rubricas. Em contextos com serviços sociais e de saúde precários e ambiente social "inadequado", como costuma ocorrer nas formações ditas periféricas, as perspectivas, a partir desta ótica, tornam-se pouco promissoras.

Mesmo assim, nos países ditos centrais, há fortes indícios de, a esta altura, a população já ter sido exposta à informação sobre os riscos a respeito da transmissão de HIV/AIDS a ponto de dispor de conhecimentos suficientes para orientar sua conduta sexual. Contudo, mais da metade dos norteamericanos pesquisados em surveys relataram não tomar nenhuma precaução quanto às possibilidades de se infectar (Guttmacher ${ }^{16}$, 1994). No Brasil, apesar da relativa insuficiência de investigações a 
este respeito, dados de estudos (ainda preliminares) apontam nesta mesma direção $\left(\right.$ Parker $\left.^{29}, 1994\right) . \mathrm{Ou}$ seja, as mensagens preventivas não se mostram alvissareiras quanto ao efetivo controle da epidemia.

Isto ocorre de tal forma que vão se tornando cada vez mais freqüentes indagações que conduzem à expectativa de se "obter um melhor entendimento sobre o comportamento humano e como mudá-lo, antes que populações inteiras de homens e mulheres relativamente jovens sucumbam diante da AIDS" (Editorial $\left.{ }^{10}, 1994\right)$. Nesta mesma perspectiva, guardadas as diferenças, tem sido noticiada na imprensa leiga uma elevação generalizada da incidência de tabagismo nas populações americanas mais jovens. Desta forma, grupos e instituições antitabagistas cogitam em adotar estratégias mais agressivas no combate ao hábito de fumar. Isto já é perceptível na mudança de retórica: fala-se agora em uma epidemia de tabagismo e se sugere que os maços de cigarro apresentem a frase "o hábito de fumar é letal" (Veja9, 1994$)$. Será que esta é uma estratégia efetiva?

\section{“RECAÍDA” DIANTE DAS “TENTAÇÕES”...}

A literatura especializada vem assinalando que os eventuais sucessos em termos de mudanças comportamentais podem não se manter ao longo do tempo. A este respeito, é importante se deter na idéia de "recaída" (relapse) a práticas sexuais não seguras (Hart e col. ${ }^{17}$, 1992). Consiste em um termo originalmente usado em estudos de seguimento para descrever a conduta de homens que haviam inicialmente adotado comportamentos sexuais seguros, mas que tiveram, posteriormente, pelo menos, um episódio desprotegido. É importante mencionar não se tratar de uma expressão veiculada pelos participantes dos estudos.

Em primeiro lugar, há críticas metodológicas aos estudos de "recaída". Por exemplo: como dimensionar o comportamento das perdas nos estudos de follow-up, os possíveis vieses de seleção (ingresso maior de indivíduos dispostos a manter práticas seguras nos estudos). Além disto, as pesquisas não conseguiram discriminar (no bom sentido), mediante variáveis epidemiológicas psicossociais ou comportamentais, as diferenças entre os "recaídos" e aqueles que nunca adotaram práticas seguras ("caídos"?). Uma possível razão para isto: o emprego do período de 30 dias anteriores como intervalo de referência aos episódios sexuais.
Em segundo lugar, é preciso discutir a noção de "segurança" na prática sexual. Há uma definição tácita, do ponto de vista preventivo, que qualquer ato penetrativo deva ser protegido, a despeito das circunstâncias. No entanto, é preciso levar em conta relações monogâmicas estáveis entre parceiros HIV negativos. Neste caso, o uso de camisinha não prejudicaria a segurança da prática de sexual, caso não fosse utilizada. Porém, é difícil determinar a freqüência desta situação (Hart e col. ${ }^{17}$, 1992).

Também podem ser feitas críticas conceituais à idéia de "recaída". Esta é, primordialmente, uma designação biomédica para enfermidades que apresentam em seu curso períodos de remissão e de recrudescimento, aonde os sinais e sintomas retornam, após aparente resolução ou controle. É usada, também em casos de adição a psicofármacos. Assim, é preciso considerar a possibilidade do comportamento sexual de risco ser visto como um mau comportamento, uma prática viciada que deva ser enfrentada com preceitos de auto-disciplina, força de vontade (Hart e col. $\left.{ }^{17}, 1992\right)$.

\section{MODELOS COMPORTAMENTAIS E PREVENÇÃO EM SAÚDE}

Alguns modelos comportamentais vêm sendo utilizados para explicar a não-aderência a recomendações de saúde. Um deles é o "Modelo das Crenças em Saúde" (MCS) (Health Belief Model). Em síntese, seus elementos são: a)suscetibilidade percebida (percepções de ameaças à saúde); b)severidade percebida (avaliações pessoais da gravidade de tais ameaças); c)benefícios percebidos (avaliações pessoais quanto à factibilidade e efetividade das recomendações para lidar com a ameaça);d)barreiras percebidas (avaliações pessoais dos obstáculos relativos às ações de saúde). O MCS postula que os indivíduos adotarão medidas preventivas conforme as percepções de severidade e suscetibilidade se os benefícios do novo comportamento superar as barreiras (Janz e Becker ${ }^{19}$, 1984).

Outra proposta é constituída pelo "Modelo da Auto-eficácia", originário da Teoria da Aprendizagem Social. Isto é, as expectativas de eficácia são os maiores determinantes quanto: a)ao início da mudança de comportamentos; b)ao dimensionamento dos esforços a serem dispendidos; c)à duração de tais esforços diante dos obstáculos (Bandura ${ }^{1}$, 1977). Há tentativas de agregar ambos modelos para dar suporte explicativo aos padrões 
de uso/não uso de preservativos (inclusive sob o efeito de psicofármacos) (Mahoney e col. ${ }^{22}$, 1995).

Estudos mostram que, apesar de altos níveis de suscetibilidade percebida ao HIV/AIDS e outras doenças sexualmente transmissíveis, comportamentos de risco (múltiplos parceiros e embriaguez durante relações sexuais) são mais relevantes para distinguir usuários esporádicos de não-usuários e de usuários consistentes de preservativos. Mas, mais importante que isto, é a constatação das medidas empregadas (e, implicitamente, os conceitos) não serem capazes de distinguir satisfatoriamente usuários consistentes de não-usuários e a assunção que "outras variáveis devem ser examinadas para melhor compreensão destas diferenças" (Mahoney e col. $\left.{ }^{22}, 1995\right)$.

Fica a impressão que estas abordagens provavelmente atingem dimensões parciais, epifenomênicas, de um fenômeno principal de outra natureza, mais complexo - relativo aos determinantes do comportamento humano. Incontrolavelmente, algo "escapa". Mas, não se trata de estudar outras variáveis e/ou combiná-las de outras formas. Está em questão a idéia de sexualidade humana assumida por estas propostas de conhecimento. E, sabemos, este terreno é controverso e eivado de preconceitos.

Modelos explicativos desta ordem têm pouco a acrescentar ao entendimento da sexualidade humana se a construção da homossexualidade masculina for marcada por categorias de análise baseadas em "perversão", enfermidade, debilidade de caráter, aberração, concupiscência etc. E, portanto, terão poucas possibilidades de sucesso em intervenções com vistas à prevenção do HIV/AIDS. E isto vale, também, mutatis mutandis, para os usuários de drogas injetáveis. Aí, também, a idéia de prevenção primária se ancora no individualismo e culpabilização da vítima, colocando uma fronteira moral entre usuários e abstêmios, e destacando a necessidade dos indivíduos resistirem a "influências negativas" de seus grupos de referência (Cohen $\left.{ }^{6}, 1993\right)$.

Tal culpabilização tende a incluir "grupos culturais" (de "risco") considerados "desviantes" das normas vigentes em nossas formações sociais (Schiller e col. ${ }^{33}$, 1994). Tal crítica, no entanto, não se constitui em novidade. Neste sentido, houve substituições aparentemente, digamos assim, "politicamente corretas" - representadas pelas categorias como as de situação/comportamento de risco (Camargo-Jr. ${ }^{4}$, 1994). Mas, é discutível se isto implica alterações significativas nas representações acerca desses grupos sociais.

\section{O ENTENDIMENTO PÚBLICO DE CONTEÚDOS CIENTÍFICOS}

Por outro lado, do ponto de vista analítico, é preciso levar em conta os papéis da retórica e seus modelos de "entendimento público" empregados nos processos de educação em saúde. Isto é, como costuma ser visto o "receptor"da informação científica. Em geral, o padrão predominante no contexto médico-epidemiológico se baseia no modelo "deficitário". Ou seja, o público é encarado como passivo, e, portanto, os conteúdos a serem veiculados requerem uma retórica que atue para acomodar fatos e métodos científicos às deficientes experiências e capacidades cognitivas do público. Assim, conforme a ideologia dominante das ciências em geral e das biociências, em particular, a comunicação é basicamente de caráter cognitivo/ racional (Gross $\left.{ }^{15}, 1994\right)$. No caso específico da epidemiologia, é clara sua adesão à uma teoria da escolha racional. Ou seja, no caso das pessoas se depararem com distintas possibilidades de ação, supostamente deverão selecionar aquela que, conforme suas crenças, as conduzam ao melhor resultado global. Portanto, a escolha racional é instrumental, orientada pelo resultado da ação (Elster $\left.{ }^{12}, 1994\right)$. O que importa reter aqui é o fato desta teoria ter o intuito de explicar a conduta humana.

Seria presumível que, em geral, indivíduos e grupos devessem basear-se nesta lógica para ampliarem sua sobrevivência, ao minimizarem os riscos impostos por uma mortalidade precoce. Isto é reforçado pelo fato do adoecimento ou da mera suspeita que o indivíduo pertença a algum "grupo de risco" se tornar motivo para sua discriminação. Portanto, a afirmação de sua "condição saudável" implica expressão positivada de sua identidade. Deste ângulo, como indica, de modo crítico, Crawford8 (1994): "O corpo saudável deve pertencer a um proprietário que o mereça" (!). O doente consiste, assim, em alguém que não administrou adequadamente (e aquele sob "maior risco" seria quem não o está administrando) os riscos existentes.

O conhecimento, ou melhor, a consciência do risco é vista como elemento crucial em qualquer política dirigida à AIDS. Pois, vale repetir, em tese: uma vez conhecendo as formas de transmissão do HIV, trata-se de uma questão de controle racional evitar ser atingido pelo vírus. A adesão ou não a este ideário serve, além do mais, para distinguir indivíduos considerados responsáveis dos nãoresponsáveis (Crawford ${ }^{8}$, 1994). 


\section{INFORMAÇÃO EM SAÚDE E MUDANCAS DE COMPORTAMENTO: "EDUCAÇÃO" DAS FORMAS DE PRAZER?}

Pois bem, apesar de tudo, torna-se inevitável indagar por que pessoas possuidoras de conhecimentos elaborados acerca dos riscos fatais ao adotarem determinados comportamentos/práticas, mesmo assim o fazem? Em outras palavras, porque tais conhecimentos não são suficientes para proporcionar a força necessária para as pessoas controlarem racionalmente suas arriscadas vontades? Será que estamos lidando com indivíduos portadores de "fraqueza de vontade"?

Parece faltar alguma reflexão acerca dos pressupostos envolvidos na idéia de "racionalidade" do receptor dessas informações com vistas a um processo dito educacional que busque alterações comportamentais. Ou seja, a discussão acerca da pertinência da concepção de indivíduo "racional", isto é, aquele que se pauta nas leis da lógica formal e, portanto, não contraria (abusivamente, pelo menos...) a teoria das probabilidades nem os cânones fundamentais da estatística (Levy $\left.{ }^{20}, 1993\right)$.

Uma tentativa de configurar o modo como a antropologia médica assume a "posição do homem racional" implica pressupostos similares sobre a "natureza humana" (Young $\left.{ }^{39}, 1981\right)$. Três deles são perfeitamente válidos também para a epidemiologia moderna, onde:

1) O conhecimento é internamente consistente de acordo com modalidades de lógica conjuntista.

2) O humano é, em essência, um ser movido pelo raciocínio - processo consciente que organiza o conhecimento para prover informações e orientar a ação.

3) O humano se comporta de maneira pragmática, baseado em modelos causais através dos quais procura predizer e controlar as ocorrências que lhe podem suceder.

Na verdade, apesar dos seus esforços, as pessoas, em geral, não costumam levar em conta predominantemente a "racionalidade" para orientar suas ações. É mais plausível conceber uma irracionalidade estrutural no humano, de tal modo que seu modus operandi parece ser orientado mais por idéias e afetos vinculados a determinados padrões pré-definidos e, por vezes, estereotipados. Aliás, é compreensível perceber que é mais "lógico" lançar mão de modelos esquemáticos familiares no processo de raciocinar (mediante imagens, analogias conhecidas), do que dispor-se a freqüentes avaliações elaboradas e trabalhosas envolvendo novos elementos. Mais, ainda: é preciso cogitar na intuição de tanto o adoecer como a exposição a determinados riscos se constituírem em modos possíveis de permanecer vivo e, por extensão, de levar a vida $\left(\mathrm{Vaz}^{36}, 1994\right)$.

No caso específico das formas de prazer sexual, é preciso indagar-se a respeito das "razões" responsáveis pelas escolhas feitas. Não se trata de uma questão de escolha racional. As pessoas estabelecem tais formas por fatores intangíveis, mescla complexa de elementos ditos biopsicosociais (ou relativos a corpo/mente/sociedade). Mas, que, não obstante, faz com que algumas pessoas tenham grandes dificuldades em substituir determinadas práticas por outras*. Isto se torna mais candente se for levado em conta as características contraditórias das sociedades ocidentais nas quais, simultaneamente, há estímulos para as pessoas consumirem múltiplas ofertas prazerosas e alerta para os riscos e malefícios destas opções. Exemplos não faltam (fora da esfera sexual, são evidentes as duplas mensagens relativas aos usos de tabaco, álcool e na gastronomia).

Neste ponto, cabe citar Elster ${ }^{12}$ (1994) sobre os intentos de orientar racionalmente o comportamento humano e os efeitos dos desejos/emoções em relação a estas propostas:

"As boas intenções perdem o poder de motivar à medida que a tentação se aproxima. A esperança reside em aprender com a experiência. Ser irracional e sabê-lo é um grande progresso em relação a ser ingênuo e impensadamente irracional. Ao lidar racionalmente com minha conhecida propensão a comportar-me irracionalmente posso fazer melhor por mim mesmo do que como vítima passiva dessa propensão. As técnicas para lidar com isso, entretanto, não são gratuitas, e às vezes o remédio é pior que a doença" ${ }^{12}$.

Se o elemento reforçador da conduta no sentido de levar em conta ameaças de danos à integridade ou à vida não fosse probabilístico, mas, sim, determinístico, isto é: certo, imediato e muito freqüente, sua eficácia talvez fosse outra. Mas, a epidemiologia, por enquanto, não dispõe de outra proposta metodológica que supere consistentemente ao modelo de risco. Talvez com o avanço das

* Como lidar, por exemplo, em termos de mudança de comportamento, com indivíduos cuja fantasia sexual fundamental se localiza na sensação de emissão ejaculatória retal? Calligaris, C. (1994). Comunicação Pessoal. 
técnicas e o reconhecimento da genética é possível surgir alterações neste quadro. Mas, serão suficientes para alterar o que O'Neill ${ }^{27}$ (1994) chama de "ignorância carnal socialmente estruturada"? Ou seja, os fatores responsáveis pelo fato de determinados indivíduos adotarem condutas necessárias*, intencionais e dificilmente controláveis. É importante pensar a sexualidade como uma dimensão particular da noção de $s i$ -

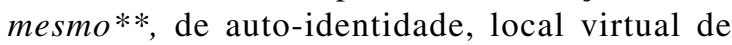
convergência de aspectos biológicos, simbólicos (narrativo-metafóricos) e socioculturais (relativos a normas e valores de determinado contexto e período).

De todo o modo, é preciso rever as disciplinas científicas em sua proposta racional de produzir dados racionais dirigidos a platéias supostamente racionais, mas, que, em seus cotidianos e nas suas intimidades, se movem por outras vias... Há uma limitação crucial de reflexão quanto ao sentido do humano na cultura científica, que se dirige preferencialmente a um conhecimento quantitativo parcial e fragmentador em busca de previsibilidade e controle. Como diz Morin ${ }^{26}$ (1991), ao criticar a figura do "perito", que deve firmar o diagnóstico pertinente a partir de seu saber, predominantemente calculador e especializado:

“(...) Tudo o que escapa à razão calculadora ao entendimento do perito, cuja insensatez principal é $a$ de não poder conhecer a insensatez humana. $O$ que é próprio do saber do perito é, não só desconhecer o que escapa ao cálculo, mas, também ignorar as interações entre os campos parcelares do conhecimento imprevisto, visto que sua experiência está voltada para resolver os problemas que se levantam em termos já conhecidos. Infelizmente para ele, e sobretudo para nós, devemos, em cada momento importante de enfrentar a paixão e a hybris, ser confrontados com a irrupção do novo e devemos cada vez mais situar todo o problema parcial no conjunto de que depende (...)".

Do ponto de vista da AIDS, os "peritos" encarregados de propor estratégias de prevenção não costumam levar em conta que a percepção do risco e os aspectos decorrentes disto estão fortemente ligados a representações tanto pessoais como sociais, no interior de significados construídos culturalmente (Parker ${ }^{29}$, 1994). Portanto, é importante estudar etnograficamente as formas como nossa desin- formação e preconceitos são socialmente estruturadas (O'Neill' $\left.{ }^{27}, 1994\right)$.

Aqui, analisa-se a epidemiologia como uma especialização caudatária da lógica da identidade, em busca de explicações acerca dos processos de adoecer nos coletivos humanos. Mas que, cada vez mais, vê-se na contingência de justificar a eficácia social de seu empreendimento.

\section{A EPIDEMIOLOGIA, A DIMENSÃO SOCIOCULTURAL E O INDIVÍDUO}

O papel da configuração sociocultural pode ser de difícil dimensionamento no processo de extrapolação dos achados de um estudo epidemiológico sobre fatores de risco. Por exemplo, a abordagem dos graves problemas como aqueles que envolvem a possível conexão entre uso de psicofármacos, maior disponibilidade a relações sexuais e, uma vez estas ocorrendo, a não-utilização de práticas sexuais seguras. Por exemplo, estudos têm mostrado que usuários de "maconha" ou, então de mais de três substâncias diferentes têm maior probabilidade de adotar comportamentos sexuais de risco. Mas, há, também, investigações que não identificam tal conexão (Hospers e Kok ${ }^{18}$, 1995).

Segundo alguns pesquisadores, o comportamento de usuários de drogas não pode ser explicado apenas pelo conhecimento da farmacologia das substâncias empregadas ou da suposta "desinibição" provocada por tais drogas. Temos aí uma complexa resultante da interação de: farmacocinética, características psicológicas pessoais, expectativas comportamentais compartilhadas no dia-a-dia, situação socioeconômica e contexto cultural (Rhodes e Stimson ${ }^{31}$, 1994).

Neste caso, a pesquisa epidemiológica produziu indicadores de comportamento sexual de risco em usuários de drogas, mas parece limitada para explicar a dinâmica desta relação.

"A inadequação da pesquisa epidemiológica convencional para gerar dados sobre a interação entre expectativas individuais, comportamento individual de risco e relações sociais, demanda uma reorientação da prática epidemiológica atual rumo a uma epidemiologia social do uso de drogas e do comportamento sexual de risco como parte de um paradigma de pesquisa social designado para investigar as relações sociais e o contexto social do

\footnotetext{
* A etimologia de necessidade aponta para algo que "não cede", "insubmisso".

** A idéia de "si-mesmo" é tematizada por diversificadas abordagens filosóficas, psicológicas e antropológicas. Uma relevante proposta de categorização sobre o tópico foi proposta por Paul Ricoeur. Ele sugere a existência de duas modalidades de identidade: uma de tipo "idem" - fixa, estável, relativa à produção do mesmo; e outra de tipo "ipse" - cambiante no decorrer do tempo, dependente do contexto, vinculada à idéia de alteridade. $\left(\right.$ Ricoeur $^{32}$, 1990).
} 
uso, conhecimento, percepções e comportamentos relativos a droga" (Rhodes e Stimson ${ }^{31}$, 1994).

Cabe indagar acerca da capacidade da epidemiologia em fazer suas afirmações de risco diante do problema das interações entre representações coletivas e individuais relativas a questões cruciais que envolvem o adoecer e o morrer. É preciso salientar não se tratar tão somente de apurar métodos para lidar com o fenômeno de interação na pesquisa epidemiológica*. Mas, sim, transformar pressupostos da própria pesquisa populacional em saúde. Nestas circunstâncias, a abordagem epidemiológica deve mudar sua ênfase em indivíduos (ou outras unidades atomizadas) rumo a "unidades globais", fruto de interações das partes, analiticamente conceptualizadas, no caso de uso de drogas e HIV/AIDS, através do entendimento das redes sociais e das "subculturas" (Rhodes e Stimson ${ }^{31}$, 1994), onde estas se localizam com suas respectivas percepções e representações, tanto sociais como individuais. Em outras palavras, é importante levar em consideração a estrutura contextual na qual as malhas de interação corpo/mente/ sociedade se instituem e são instituídas. No caso do hábito de fumar, por exemplo, a ênfase preventivista é colocada no comportamento tabagista do indivíduo - no pólo do consumo - ao invés de dirigir-se, também, às formas organizadas de produção e promoção do tabagismo (Wing ${ }^{38}$, 1994).

Em relação ao HIV/AIDS, pesquisas antropológicas vêm discutindo a efetividade dos seus programas de educação dirigidos ao nível da responsabilidade pessoal quanto a condutas que levassem à redução do risco. Mais especificamente, procuram avaliar motivos porque muitas pessoas tendem a não se perceberem como sujeitas à ameaça de infecção pelo HIV (Lupton e col. ${ }^{21}$, 1995).

Tais programas, em geral, deixam de lado aspectos ligados à dimensão interativa do risco, ou seja, o fato das relações com os "outros" e seus aspectos sociais e simbólicos deverem, também, ser levados em consideração. Neste sentido, a sugestão ao uso de preservativos pode insinuar significados de promiscuidade, degeneração moral, contaminação (daí serem, usados, também, com vistas à proteção contra doenças venéreas) - incompatíveis com relações sexuais baseadas na confiança no parceiro. Isto tenderá a ser visto como sério empecilho à possível proposta de intimidade veiculada por relações sexuais $\left(\right.$ Sibthorpe $\left.^{34}, 1992\right)$.
Uma pesquisa qualitativa realizada na Austrália sobre o emprego de preservativos por parceiros heterossexuais mostrou que a natureza interpessoal das relações sexuais influencia seu respectivo uso/ não-uso. Tal investigação sugere a existência de dois níveis de diálogos sobre a "camisinha": 1) interpessoal - diz respeito às "negociações" nos encontros sexuais; 2)discursivos - relacionados a um esquema de referência mediante o qual as pessoas avaliam e procuram compreender suas experiências sexuais. Tais diálogos modelam as mediações que determinam o uso/não-uso de preservativos. Mas, em síntese, a sexualidade está intimamente ligada às construções de gênero - no interior de um processo de constituição de uma noção de si-mesmo, quanto ao que seja "comportamento sexual 'apropriado"" que definem a escolha de usar ou não preservativos (Browne e Minichiello ${ }^{3}$, 1994).

Em relação ao contexto dos homens que fazem sexo entre si, tanto Costa ${ }^{7}$ (1994) como Parker $^{28}$ (1994) assinalam o papel capital dos significados quanto à "identidade homoerótica" para a participação efetiva em propostas preventivas compartilhadas para reduzir o risco de infecção e transmissão do HIV.

Outro estudo antropológico foi realizado com 16 mulheres atendidas pelo Centro de Referência da Prefeitura na cidade portuária de Santos (São Paulo), reconhecida por constituir-se em local de grave incidência de HIV/AIDS. Seus parceiros tinham história de uso de drogas. Mesmo sabendo dos riscos que corriam, essas mulheres mantinham relações sexuais desprotegidas. Atribuíram à fatalidade o fato de terem se tornado soropositivas e não responsabilizaram seus parceiros. Seus "comportamentos de risco" eram justificados pela manutenção da relação amorosa (Martin $\left.{ }^{24}, 1995\right)$.

“(...) É a interação que conta, e uma epidemiologia na qual etiologias são vistas como causas mecânicas e indivíduos como conglomerados de fatores de risco estatisticamente correlacionados leva, ela própria, à frustração dos profissionais envolvidos na promoção de saúde e à tentação de culpar as vítimas por recusarem a escolher estilos de vida 'corretos'. É somente encarando o comportamento tanto de pacientes em potencial e possíveis curadores em seus contextos culturais compartilhados, mas, sempre fluidos, que as relações entre desejos, identidades e as implicações

* Por sinal, há o reconhecimento, mesmo neste nível de preocupação, da limitação dos métodos para chegar a conclusões definitivas sobre efeitos sinergísticos ou antagonistas em relação aos efeitos conjuntos de dois fatores de risco. Thompson ${ }^{35}, 1991$. 
das mudanças para cada um podem ser vistas de forma a tornarem possiveis as escolhas reais" (Frankenberg $\left.{ }^{13}, 1994\right)$.

\section{AS REDES SOCIOHISTÓRICAS}

Levando em conta a importância das dimensões interpessoais, um recente desenvolvimento em técnicas de investigação no campo epidemiológico propõe-se a abordar níveis de análise para além de unidades individualizadas. As denominadas abordagens sociohistóricas de redes vêm estudando, justamente, a epidemia de HIV/AIDS. Assim, as probabilidades: a) de estar infectado pelo HIV; b) de assumir comportamentos de risco; c) de tais comportamentos de risco levarem à infecção (e, também as abordagens de prevenção ao HIV) podem ser encaradas como dependentes de estruturas e processos históricos e sociais referidos a escalas mais amplas de observação (como já mencionado). Tais fatores exercem efeitos sobre a epidemia mediante suas influências sobre as formas de interação pessoal, tanto em termos sexuais como nas práticas de compartilhamento de seringas (Friedman e col. ${ }^{14}$, 1994).

Portanto, elementos pertencentes a outras escalas de organização afetam as redes sociais, e, por sua vez, também, interferem nas redes de risco onde circulam os agentes patogênicos de diversas doenças sexualmente transmissíveis. Redes sociais seriam relações que influenciam idéias, normas e condutas. Redes de risco consistiriam em comportamentos e materiais de transferência (seringas compartilhadas descuidadamente, por exemplo) passíveis de transmitir o HIV. Como seria presumível, ambas podem apresentar áreas de superposição.

As informações para configurar as redes podem ser obtidas através de questionários pessoais que indagam sobre dados sociodemográficos e biográficos, comportamentos sexuais e uso de drogas, história clínica, crenças em relação à saúde, papéis sociais na cultura da droga, normas de convívio entre pares. As redes são montadas pela indicação de parceiros e companheiros (até 10 pessoas, com as quais mantiveram contatos não casuais e/ou comportamentos de risco, nos últimos 30 dias), além de outras informações sobre seus comportamentos de risco, tanto isolada como conjuntamente.
Os indivíduos são considerados "vinculados" caso um ou ambos tenha referido injeção conjunta de drogas, relações sexuais entre si, ou outra interação não casual. Tais vinculações são validadas por contatos pessoais com entrevistadores, por observação etnográfica, pelo pareamento de características identificadas.

Mesmo assim, há limitações nos dados, em função de sub-registro, da impossibilidade de se obter amostras aleatórias dessas populações, das restrições oriundas das técnicas analíticas, das modificações das redes diante da "antiguidade" da epidemia (15 anos em Nova York), além de inviabilizar a delimitação do sentido da infecção. De qualquer forma, temos indivíduos, com determinados padrões de exposição à infecção, de acordo com seus comportamentos de risco (um nível de análise) que são agrupados conforme as redes interativas que estabelecem (outro nível). Estes procedimentos vêm revelando novas dimensões no estudo e na prevenção da epidemia (Friedman e col. $\left..^{14}, 1994\right)$.

A pesquisa populacional em saúde vêm se desenvolvendo no sentido de incorporar técnicas sofisticadas de modelagem com abordagens qualitativas. Estão se tornando mais frequientes estratégias investigativas híbridas constituídas por desenhos qualitativos aninhados no interior do aparato metodológico quantitativo*. Por exemplo, em uma proposta de estudo experimental de eficácia de uma vacina contra HIV/AIDS, inclui-se uma abordagem sociocomportamental qualitativa, mediante história de vida e grupos focais (Carvalheiro e col. $\left.{ }^{5}, 1994\right)$.

\section{EPIDEMIOLOGIA, ADOECIMENTO E ÉTICA}

Apesar da pretensão de alguns epidemiologistas no sentido de sua disciplina ter a "dureza" (hardness) das chamadas ciências naturais, é difícil negar as marcadas características teórico-metodológicas de ciências ditas "sociais" apresentadas pela epidemiologia**. Segundo Elster ${ }^{12}$ (1994), o propósito de qualquer explicação causal no campo das ciências sociais deve, pelo menos, sugerir mecanismos (sem relação com a ótica mecanicista geral relativa à idéia de funcionamento social) que constituem possíveis padrões causais. Assim sendo,

\footnotetext{
* Há uma série de questões metodológicas importantes que não pertencem ao escopo de presente trabalho. Envolvem amostragem, tratamento das perdas, densidade e interconectividade no interior das redes etc. Para os interessados, sugere-se consultar Bastos ${ }^{2}, 1995$.

** Para os epidemiologistas como Olli Miettinen, esta questão não se coloca. Pois, não considera a epidemiologia uma ciência, e, sim, uma disciplina da saúde pública (ou medicina comunitária). Sua função essencial não é averigüar aspectos etiológicos das doenças, mas, verificar ocorrência de agravos à saúde e desenvolver estudos de intervenção (Miettinen ${ }^{25}$, 1985).
} 
transitar de tais mecanismos para uma teoria unificada implica a necessidade de delimitar previamente as condições de entrada em ação de mecanismos específicos. No presente "estado da arte", há dúvidas quanto ao alcance das propostas destes domínios científicos em produzirem leis gerais sobre o comportamento humano (Elster ${ }^{12}$, 1994), e suas relações com os modos de adoecer. Mesmo que tenhamos mapeado o genoma humano, as interações gens/ambiente/psiquismo/cultura não parecem passíveis de serem decifradas tão cedo.

O surgimento da AIDS ampliou as preocupações e ansiedades quanto à idéia de racionalidade, às fronteiras entre os corpos, à contaminação dos humores e à noção de (in)competência imunológica (Lupton e col. $\left.{ }^{21}, 1995\right)$. De acordo com o poeta e

\section{REFERÊNCIAS BIBLIOGRÁFICAS}

1. BANDURA, A. Self-efficacy: toward a unifying theory of behavioral change. Psychol. Rev., 84: 191-215, 1977.

2. BASTOS, F.I.P.M. Ruína e reconstrução. AIDS e drogas injetáveis na veia contemporânea. Rio de Janeiro, 1995. [Tese de Doutorado - Escola Nacional de Saúde Pública].

3. BROWNE, J. \& MINICHIELLO, V. The Condom: Why more people don't put it on?. Sociol. Health Illness., 16 : 228-49, 1994

4. CAMARGO-Jr., K.R. As ciências da AIDS e a AIDS das ciências. O discurso médico e a construção da AIDS. Rio de Janeiro, Relume-Dumará, 1994.

5. CARVALHEIRO, J.R. Vacina contra HIV/AIDS: estudo de factibilidade em uma coorte de homossexuais: o caso de São Paulo. In: IV Congresso Brasileiro de Saúde Coletiva, $4^{\circ}$, Recife, 1994. Caderno de Resumos. Recife, 1994.

6. COHEN, J. Achieving a reduction in drug-related harm through education. In: Heather, N.; Wodak, A.; Nadelmann, E.; O'Hare, P. orgs. Psychoative drugs and harm reduction: from faith to science. London, Whurr Publ. 1994. p. 65-77.

7. COSTA, J.F. O homoerotismo diante da AIDS. In: Parker, R.; Bastos, C.; Galvão, J.; Pedrosa, J.S. A AIDS no Brasil (1982-1992). Rio de Janeiro, Relume-Dumará, 1994 p. 151216.

8. CRAWFORD, R. The boundaries of the self and the unheathy other: reflections on health, culture and AIDS. Soc. Sci. Med.; 38: 1347-65, 1994.

9. DIAGNÓSTICO devastador. Veja, 27 (39): 94, 1994.

10. EDITORIAL: More bad news on AIDS. Nature, 371 (6489): 400, 1994.

11. DANZIGER, R. The social impact of HIV/AIDS in developing countries. Soc. Sci. Med., 39: 905-17, 1994. pensador mexicano, (não apenas no caso específico da AIDS, pois se aplica a outras moléstias), não bastam avanços terapêuticos ou profiláticos para vencê-la(s). Mas, sim, "um ideal de vida fundado na liberdade e na entrega" $\left(\mathrm{Paz}^{30}, 1994\right)$. No caso da AIDS, é perceptível o fato de precisarmos de uma ética erótica. Mais do que isto, em relação ao viver (e adoecer), são essenciais propostas éticas realistas no interior dos empreendimentos ditos científicos, onde a experiência humana, por não se adequar aos preceitos definidores de um objeto científico, não seja considerada irrelevante. Enfim, é cada vez mais difícil deixar de admitir as limitações geradas por esta premissa tanto nos atuais modos de adoecer como nas proposições de estudá-los, tratá-los e preveni-los.

12. ELSTER, J. Peças e engrenagens das ciências sociais. Rio de Janeiro, Relume-Dumará, 1994.

13. FRANKENBERG, R.J. The impact of HIV/AIDS on concepts relating to risk and culture within the British community epidemiology: candidates or targets for prevention? Soc. Sci. Med., 38: 1325-35, 1994.

14. FRIEDMAN, S.R.; NEAIGUS, A.; JOSE, B.; CURTIS, R.; GOLDSTEIN, M.; SOTHERAN, J.L.; WENSTON, J.; LATKIN, C.A.; des JARLAIS, D.C. Network and sociohistorical approaches to the HIV epidemic among drug injectors: conferences on biopsychosocial aspects of AIDS. Brighton, 1994.

15. GROSS, A.O. The roles of rhetoric in the public understanding of science. Public Understanding Sci., 3: 3-24, 1994.

16. GUTTMACHER, S. The evolution of a public health policy: health care and the transmisson of HIV. Int. J. Health Serv., 24: 535-48, 1994.

17. HART, G.; BOULTON, M.; FITZPATRICK, R.; MCLEAN, J.; DAWSON, J. Relapse' to unsafe sexual behavior among gay men: a critique of recent behavioral HIV/AIDS research. Sociol. Health Illness., 14: 216 - 32, 1992.

18. HOSPERS, H.J. \& KOK, G. Determinants of safe and risktaking sexual behavior among gay men: a review. AIDS Educ. Prev., 7: 74-94, 1995.

19. JANZ, N.K. \& BECKER, M.H. The health belief model: a decade later. Health Educ. Q., 11: 1-47, 1984.

20. LEVY, P. As tecnologias da inteligência: o futuro do pensamento na era da informática. Rio de Janeiro, Ed. 34, 1993.

21. LUPTON, D.; MCCARTHY, S; CHAPMAN, S. Panic bodies': discourses on risk and HIV antibody testing. Sociol_.Health Illness., 17:89-108, 1995. 
22. MAHONEY, C.A.; THOMBS, D.L.; FORD, O.J. Health belief and self- efficacy models: their utility in explaining college student condom use. AIDS Educ. Prev., 7: 32-49, 1995.

23. MANN, J.; TARANTOLA, D.J.M.; NETTER, T.W. orgs. 1993. A AIDS no Mundo. Rio de Janeiro, Relume-Dumará, 1993.

24. MARTIN, D. Mulheres e AIDS: uma abordagem antropológica. São Paulo, 1995. [Dissertação de Mestrado em Antropologia - Faculdade de Filosofia, Letras e Ciências Humanas da USP].

25. MIETTINEN, O.S. Theoretical epidemiology: principles of ocurrence research in medicine. New York, Wiley, 1985.

26. MORIN, E. O método IV. As idéias: a sua natureza, vida, habitat e organização. Lisboa, Publ. Europa-América, 1991.

27. O'NEILL, J. A AIDS e o pânico globalizante. In: Featherstone, M. Cultura global nacionalismo, globalização e modernidade. Petrópolis, Ed. Vozes, 1994. p. 349-63.

28. PARKER, R.G. Sexo entre homens: consciência da AIDS e comportamento sexual entre homens homosexuais e bissexuais no Brasil. In: Parker, R.; Bastos, C.; Galvão, J.; Pedrosa, J.S. A AIDS no Brasil (1982-1992). Rio de Janeiro, Relume-Dumará, 1994, p. 129-50.

29. PARKER, R.J. A construção da solidariedade. AIDS, sexualidade e política no Brasil. Rio de Janeiro, RelumeDumará, 1994.

30. PAZ, O. A dupla chama: amor e erotismo. Rio de Janeiro, Ed. Siciliano, 1994.
31. RHODES, T. \& STIMSON, G.V. What is the relationship between drug taking and sexual risk? social relations and Social research. Sociol. Health Illness., 16: 209-28, 1994.

32. RICOEUR, P. O si-mesmo como um outro. Campinas, Ed Papirus, 1990.

33. SCHILLER, N.G.; CRYSTAL, S.; LEWELLEN, D. Risky Business; the cultural construction of AIDS risk groups. Soc. Sci. Med., 38: 1337 - 46, 1994.

34. SIBTHORPE, B. The social contruction of sexual relationships as a determinant of HIV risk perception and condom use among injection drug users. Med. Anthropol. Q., 6: 255 $-70,1992$.

35. THOMPSON, W.D. Effect modification and the the limits of biological inference from epidemiologic date. J. Clin. Epidem., 44: 221-32, 1991.

36. VAZ, P.R.G. O inconsciente artificial. Rio de Janeiro, 1994. [Tese de Doutorado - Escola de Comunicação da Universidade Federal do Rio de Janeiro].

37. WEISSE, C.S.; TURBIASZ, A.A.; WHITNEY, D.J. Behavioral training and AIDS risk reduction: overcoming barriers to condom use. AIDS Educ. Prev., 7: 50-9, 1995.

39. WING, S. Limits of epidemiology. Med. Global Survival. 1: 74-86, 1994.

40. YOUNG, A. When rational men fall sick: an inquiry into some assumptions made by medical anthropologists. Cult. Med. Psychiatry, 5: 317-35, 1981. 